\title{
Energy sustainability analysis based on SDGs for developing countries
}

\author{
Ali (Armin) Razmjoo ${ }^{\mathrm{a},}$, Andreas Sumper ${ }^{\mathrm{a}, \mathrm{b}}$, Afshin Davarpanah ${ }^{\mathrm{c}}$ \\ a Escola Tècnica Superior d'Enginyeria Industrial de Barcelona (ETSEIB), Universitat Politècnica de Catalunya \\ (UPC), Av. Diagonal, 647, 08028 Barcelona, Spain \\ ${ }^{b}$ Centre d'Innovació Tecnològica en Convertidors Estàtics i Accionaments (CITCEA-UPC), Escola Tècnica Superior \\ d'Enginyeria Industrial de Barcelona (ETSEIB), Universitat Politècnica de Catalunya (UPC), Av. Diagonal, 647, P1. 2, \\ 08028 Barcelona, Spain \\ c Department of Petroleum Engineering, Science and Research Branch, Islamic Azad University, Tehran, Iran \\ *Corresponding Email; Afshin.Davarpanah@srbiau.ac.ir
}

\begin{abstract}
Electrical production for residential areas is one of the most important goals of SDGs (17 UN goal) and UN-Habitat III (14 goals) that can be achieved by renewable energy. Now, renewable energy is a significant issue that must be considered seriously as a policy and in order to achieve energy sustainability on a global scale especially in whole developing countries. Also, since the role of renewable energy in sustainable development is remarkable, thus this article presents a comprehensive discussion of energy sustainability for urban areas with related energy indicators and technical analysis of a Hybrid Power System to show the importance of renewable energy to gain energy sustainability. This paper presents the feasibility of using PV-DG hybrid systems as the reliable energy by an economic and technical analysis in one of the southern cities of Iran use of HOMER software. Regarding the high average of solar radiation that is about 5.4 $\mathrm{kWh} / \mathrm{m} 2 / \mathrm{d}$ in Chabahar city, technical analysis of this system demonstrates that this city has a high capacity to producing the electrical energy via PV-diesel hybrid system with total electrical production amount of $10,575 \mathrm{kWh} / \mathrm{yr}$ from PV $(8,447 \mathrm{kWh} / \mathrm{yr})$ and Diesel system $(2,128 \mathrm{kWh} / \mathrm{yr})$. For do this work at the first, the required data is gathered from the meteorological organization of Iran and then technical and economic analysis is conducted with the Homer software. This study regarding the high potential of solar energy of Chabahar city shows that to achieve development especially in the energy sustainability field needs to
\end{abstract}


implementing proper actions such as enough investment on clean energy and using renewable energy for electrical production.

Keywords: Energy sustainability, Indicators, Hybrid system, Renewable energy, Electrical production

\section{Introduction}

Human activities in recent years with the excessive emission of greenhouse gases have had a negative impact on the increase in global temperatures (Jahangiri, Rizi, and Shamsabadi 2018). In this regard, one of the best ways to control it, move toward sustainability with more use of renewable energy (Razmjoo and Davarpanah 2018). Today, the use of renewable energy which is a good alternative to fossil fuels has been accepted in many countries of the world (Bogdanov and Breyer 2016). Also use of more renewable energy instead of fossil fuels will be of great help to the environment (Novan 2015, Davarpanah 2018). Among renewable energies, wind and solar are most used to energy supply (Razmjoo et al. 2017). Now, the utilization of renewable energy rose, and in many countries, a remarkable part of the required energy is supplied by renewable energy(Jahangiri et al. 2015). Importance of renewable energy caused many researchers in different zones of the world to have much research on renewable energy that can be mentioned some of them (Srivastava and Giri 2016). Potential and prospects of Solar energy as a reliable source has been carried out by E Kabir et al. in this study discussed the advantages and disadvantages of solar energy technologies. Despite different problems such as low solar cell efficiencies and economic problems, they are believed that still, the development of novel solar power technologies is one of the best way considered to supply of worldwide demand for energy (Kabir et al. 2018). A scientific study regarding energy and sustainable development carried out by Kaygusuz, K et al. In this study has been considered an energy situation for developing countries. They mentioned that access to electrical energy equally and implementing effective indicators are important factors to achieve progress and sustainable development (Kaygusuz 2012). Sen S et al., in an article, discussed different opportunities, barriers, and issues with renewable energy development in the country. In this article, they showed that Renewable energy in addition to mitigating climate change would lead to a sustainable social and economic development (Sen 
and Ganguly 2017). Laith M. Halabi et al., present a comprehensive investigation study of hybrid renewable energy system design for a tropical climate zone with a deeply techno-economic evaluation and with an environmental aspects attitude (Halabi and Mekhilef 2018). Ellabban O et al. investigated the current status of renewable energy resources and prospects about enabling technology. On the other hand, they in this study investigated the importance of power electronics converter for application in renewable energy and the integration of renewable energy resources into the smart grid system (Ellabban, Abu-Rub, and Blaabjerg 2014). A study regarding renewable energy development for sustainable development goals in Tanzania country has been done by Bishoge $\mathrm{O}$ et al. They in this study showed that one of the appropriate ways to achieve affordable and accessible energy in Tanzania, is the use of renewable energy. Also, in this study renewable energy are emphasized as a way for sustainable development (Bishoge, Zhang, and Mushi 2018). Marquez MJ et al., investigated and measured for Barcelona and Malaga cities the energy sustainability. They based on different important factors such as the features of the energy end-use, energy systems, and flows, etc., s.uggested a methodology in order to evaluate the energy sustainability of a city (MarquezBallesteros et al. 2018). Boran FE et al. evaluated the different technologies of renewable energy to electricity generation. They used of Intuitionistic Fuzzy TOPSIS method for doing it in Turkey country. Indeed in this study, they for a long-term application evaluated the effective and well-known technologies regarding renewable energies (Boran, Boran, and Menlik 2012). Halabi LM et al., based on previous surveys and information, investigated two decentralized power stations in the area of Malaysia that were combined with PV, diesel generators, system converters, and reserve batteries. In this study also, using HOMER software the operational behaviors of variety PV influence levels were investigated in order to an exact measure of the effect of PV integration.(Halabi et al. 2017). Analysis of off-grid electricity system in a Scotland island carried out by Chmiel $\mathrm{Z}$ et al. It was a real example of a successful off-grid electrification system. They in this study showed that to supply the electricity needs of a community, it is possible to use electricity 24/7 from a hybrid off-grid system because off-grid energy systems are as an independent source of energy to satisfy the electricity needs (Chmiel and Bhattacharyya 2015). An economic assessment for a combined energy wind energy storage system was carried out based on a theory by X Han et al. They 
investigated, the benefits of the installation of the energy storage system in order to improve the electric quality and obtain more economic advantages )Han et al. 2017(. Guichia A et al., presented a new management algorithm to optimize the produced energy in order to allow the system for having proper action as a distributed source inside the tool network (Guichi et al. 2018). Monowar H et al., a with a deeply operational efficiency analysis presented a combination of several optimal independent renewable energy combinative systems for a large recreational center. They obtained that the best-optimized system in this study is including PV, wind, diesel, converter, battery system (Hossain, Mekhilef, and Olatomiwa 2017). Hosseini SE et al. are presented with a review of green energy potentials in Iran an evaluation of renewable energy potentials. They in this study, investigated the alternative fuel and renewable resources to reduce fossil fuel consumption in the future for Iran (Hosseini et al. 2013). Jahangiri $M$ et al. investigated the potential of a hybrid solar cell, wind turbine, and biomass system in order to electrical supply for the residential building. They showed that, from the economic point of view, solar cells are proper for most climate kind and humid climates, and biomass is appropriate to moderate and humid climates (Vahdatpour et al. 2018). Shezan, S.A., et al., analyzed the performance of a hybrid energy system. This hybrid system consisted of wind-PV and diesel. They using HOMER software, simulated and designed this system for a small community with an average load demand of $33 \mathrm{kWh} /$ day. Also, the amount of NPC and CO2 emission for this system was respectively about $29.65 \%$ and 16 tons per year compared to the other power plants (Shezan et al. 2016). In this study, based on UN goals and Urban Themes targets which emphases on the move toward the energy sustainability by renewable energy, has been investigated the energy potential of the Chabahar city. This study has two main parts. First of all, in this study presents a comprehensive discussion about energy sustainability including related indicators and second of all, is investigate a PVDG system for a residential area. We discuss regarding the key role of policy to develop energy sustainability and investigate a PV-diesel system for Chabahar city.

\subsection{The key role of policy to develop energy sustainability}

To achieve energy sustainability goals, having a strong and accounted policy program is required. It can lead to more attraction of public support to effectively implement plans and to achieve high efficiency in 
energy. A key issue to achieve sustainable development especially in the energy field has an appropriate policy and in this regard policy methods and policymakers are most influential (Helm 2002). Implementing energy policy need to public support. Implementing participatory processes is not easy and in this regard diversity of stakeholders' rationales must be considered, and use appropriate method and instruments for participation (Wesselink et al. 2011). It shows high participation is important to reaching success (Bäckstrand 2003). Policymakers to success in implementing policies in particular in sustainability must be integrated the stakeholder perceptions in decision-making. It can improve the policy design and implementation determined policies and prevent public opposition (Doelle and Sinclair 2006). On the other hand, providing energy for the present and future generation is an important subject that needs an appropriate policy. indeed, energy security is a serious challenge in the present century and is extremely involved with policy. Policymakers consist of the body of government. Thus they are an important factor in the decision making and for monitoring on the progress (Mainali et al. 2014). To overcome related problems with energy, governments should focus on implementing proper measurements in line with the assigned target to mitigate existing problems and in order to enhanced effectiveness of policies. They can use different indicators which are as an effective tool for development and sustainability. Indeed, indicators play a key role in implement energy sustainability and have the key role of policy-making to implement appropriate indicators (Sovacool and Mukherjee 2011). Since the welfare of humans with considering environment are the most important issue in the world, thus all human activities should be performed in the line to satisfy this reality. Table 1 shows the $17 \mathrm{UN}$ goals by the 2030 year that are arranged based on four important indexes in this study.

Table 1 . The $17 \mathrm{UN}$ goals by the 2030 year based on four important indexes in this study.

\begin{tabular}{|c|c|c|c|c|}
\hline Indicators & Policy & Economy & Environment & Social \\
\hline No poverty & $\sqrt{ }$ & $\sqrt{ }$ & $\mathrm{x}$ & $\sqrt{ }$ \\
\hline Zero Hunger & $\sqrt{ }$ & $\sqrt{ }$ & $\mathrm{x}$ & $\sqrt{ }$ \\
\hline Good health and well-being & $\sqrt{ }$ & $\mathrm{x}$ & $\sqrt{ }$ & $\sqrt{ }$ \\
\hline Quality education & $\sqrt{ }$ & $\mathrm{x}$ & $\mathrm{x}$ & $\sqrt{ }$ \\
\hline Gender Equality & $\sqrt{ }$ & $\mathrm{x}$ & $\mathrm{x}$ & $\sqrt{ }$ \\
\hline Clean water and sanitation & $\sqrt{ }$ & $\mathrm{x}$ & $\sqrt{ }$ & $\sqrt{ }$ \\
\hline Affordable and clean energy & $\sqrt{ }$ & $\sqrt{ }$ & $\sqrt{ }$ & $\sqrt{ }$ \\
\hline
\end{tabular}


Decent work and economic growth Industry, Innovation, and Infrastructure

Reduced Inequality

Sustainable Cities and Communities

Responsible Consumption and Production

Climate action

Life Below Water

Life on Land

Peace and Justice Strong Institutions

Partnerships to achieve the Goal

$\sqrt{ }$
$\sqrt{ }$
$\sqrt{ }$
$\sqrt{ }$
$\sqrt{ }$
$\sqrt{ }$
$\sqrt{ }$
$\sqrt{ }$
$\sqrt{ }$

$\begin{array}{lll}\sqrt{ } & \mathbf{x} & \sqrt{ } \\ \sqrt{ } & \mathbf{x} & \sqrt{ } \\ \mathbf{x} & \sqrt{ } & \sqrt{ } \\ \sqrt{ } & \sqrt{ } & \sqrt{ } \\ \mathbf{x} & \sqrt{ } & \sqrt{ } \\ \mathbf{x} & \sqrt{ } & \mathrm{x} \\ \mathbf{x} & \sqrt{ } & \sqrt{ } \\ \mathbf{x} & \mathrm{x} & \sqrt{ } \\ \mathbf{x} & \mathrm{x} & \sqrt{ } \\ \mathbf{x} & & \end{array}$

Also, Table 2 shows the 14 Urban themes based on four important indexes and related the methodology of this study. Policy and social indexes as it is clear are most important than other indexes although none of them should be ignored.

Table 2. The 14 Urban themes based on four important indexes in this study

\begin{tabular}{lcccc}
\hline Indicators & Policy & Economy & Environment & Social \\
\hline Legislation & $\sqrt{ }$ & $\mathrm{x}$ & $\mathrm{x}$ & $\sqrt{ }$ \\
Mobility & $\sqrt{ }$ & $\mathrm{x}$ & $\mathrm{x}$ & $\sqrt{ }$ \\
Housing \& slum upgrading & $\mathrm{x}$ & $\mathrm{x}$ & $\mathrm{x}$ & $\sqrt{ }$ \\
Safety & $\sqrt{ }$ & $\mathrm{x}$ & $\mathrm{x}$ & $\sqrt{ }$ \\
Climate change & $\sqrt{ }$ & $\mathrm{x}$ & $\sqrt{ }$ & $\mathrm{x}$ \\
Gender & $\sqrt{ }$ & $\sqrt{ }$ & $\mathrm{x}$ & $\sqrt{ }$ \\
Planning \& Design & $\sqrt{ }$ & $\mathrm{x}$ & $\mathrm{x}$ & $\sqrt{ }$ \\
Economy & $\mathrm{x}$ & $\sqrt{ }$ & $\mathrm{x}$ & $\sqrt{ }$ \\
Reconstruction & $\sqrt{ }$ & $\mathrm{x}$ & $\mathrm{x}$ & $\sqrt{ }$ \\
Resiliency & $\sqrt{ }$ & $\mathrm{x}$ & $\mathrm{x}$ & $\sqrt{ }$ \\
Human rights & $\sqrt{ }$ & $\mathrm{x}$ & $\mathrm{x}$ & $\sqrt{ }$ \\
Water \& sanitation & $\mathrm{x}$ & $\mathrm{x}$ & $\mathrm{V}$ & $\sqrt{ }$ \\
Youth & $\mathrm{x}$ & $\mathrm{x}$ & $\mathrm{x}$ & $\sqrt{ }$ \\
Energy & $\sqrt{ }$ & $\sqrt{ }$ & & \\
& & & & \\
\hline
\end{tabular}

\subsection{Renewable energy, environment issue, and energy sustainability}

Fossil fuels are the main cause of air pollution and major sources to produce a large amount of carbon dioxide in the air which led to an increase in global warming (Godina et al. 2018). In this regard, achieving energy sustainability using renewable energy is one of the effective ways of reducing fossil fuels improving energy efficiency and is an important target for our future (Gugul, Koksal, and Ugursal 2018). Since energy 
sustainability can meet providing the needs of our present generations without hurt to future generations in particular regarding energy, thus, in this regard, subjects such as access to energy, energy affordable, clean and abundant are most important for us (Clemens et al. 2018). Sustainable energy is abundant energy that we are capable of using for a long time. On the other hand, Sustainable energy helps us to reduce greenhouse gas emissions and prevent damage to the environment. Thus, since most times is accessing sources energy like sunlight and wind is possible, therefore, move towards sustainable energy should be continued and the approaches for sustainable energy should be encouraged (Çakir, Comakli, and Yüksel 2012). Fig 1 shows the key role of renewable energy to reduce $\mathrm{CO} 2$ emission and achieve sustainable development, especially in the energy and sustainability field.

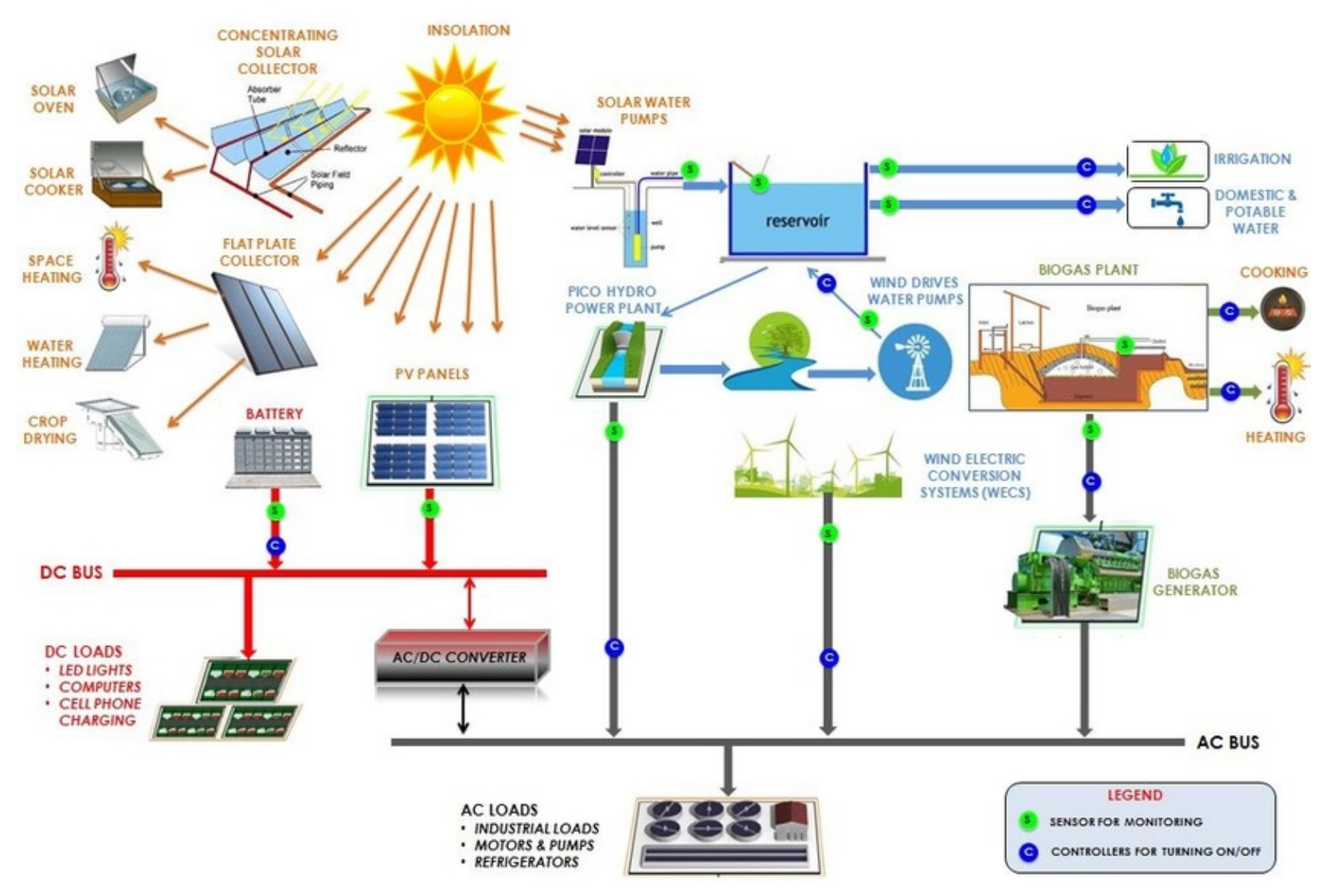


Fig 1. The key role of renewable energy to reduce $\mathrm{CO} 2$ emission and achieve sustainable development especially in the energy and sustainability field (Maheshwari and Ramakumar 2017)

\subsection{Electrical production by renewable energy in the line of energy sustainability}

The use of renewable energy today is one of the most appropriate ways of generating electricity ( ̌́úri et al. 2007) and achieve to energy sustainability (Neves and Leal 2010, Alazraque-Cherni 2008). Various countries with long-term planning and investment in renewable energy are trying to provide a significant portion of their future energy needs in the future (Dincer 2011). Among different kind of renewable energies, the role of wind and solar energy is significant for electrical production (Zhou et al. 2010). Today importance of smart grid system is vital for energy supply and a safe future. Fig 2 shows the evolutionary feature of the smart grid that can create bidirectional flows of energy and communication. As can see this system combines a small wind turbine and photovoltaic solar panels. In this system in order to supply energy to an inverter is used of the extracted energy.

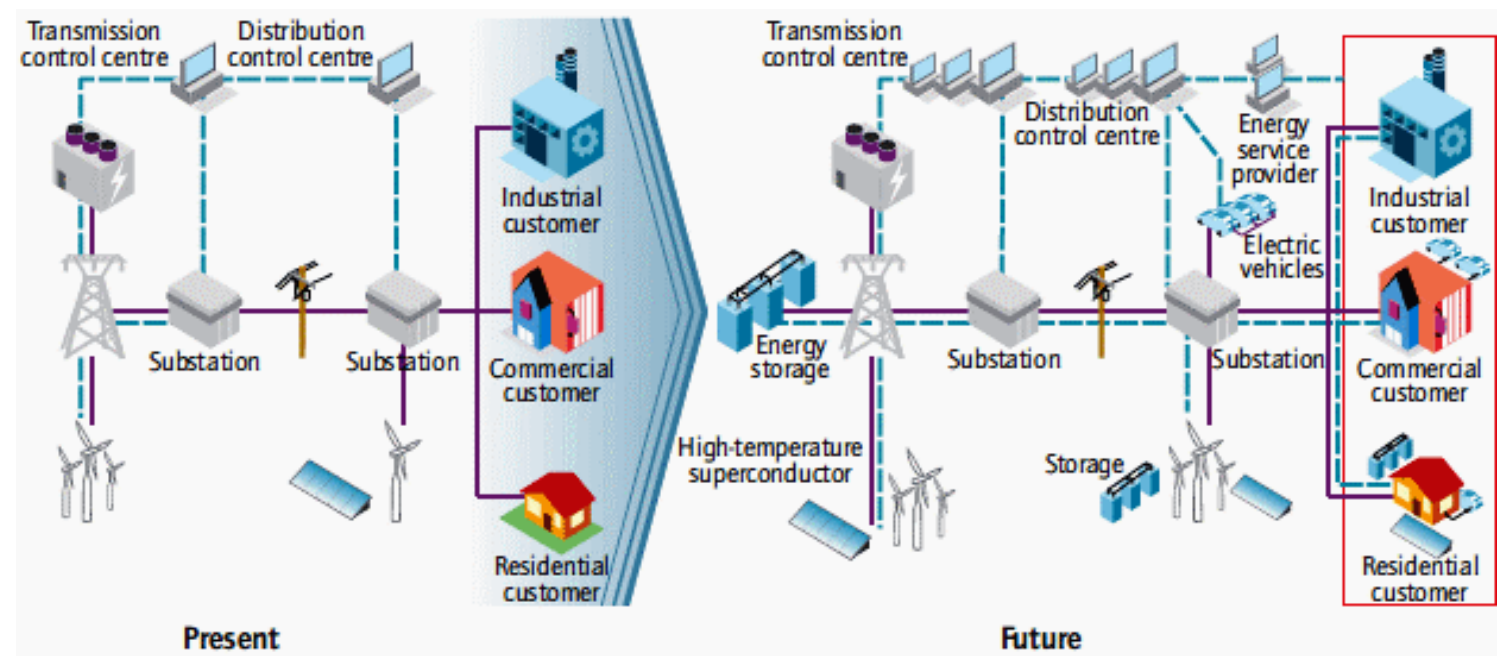

Fig 2. Smarter electricity systems (Ellabban, Abu-Rub, and Blaabjerg 2014)

Table 3 that obtained based data of international energy agency (IEA) shows the total energy production for Iran country from 2012 to 2016 years. As it specified by blue color in this Table, the share of 
renewable energies in total energy production is low which this shows the most amount of energy production for Iran is by fossil fuels.

Table 3. Total energy production for Iran country from 2012 to 2016 years [IEA]

\begin{tabular}{ccccccccccc}
\hline $\begin{array}{c}\text { Production/ } \\
\text { Year }\end{array}$ & Coal & $\begin{array}{c}\text { Crude } \\
\text { oil }\end{array}$ & Natural gas & Nuclear & Hydro & $\begin{array}{c}\text { Geothermal and } \\
\text { Solar }\end{array}$ & $\begin{array}{c}\text { Biofuels and } \\
\text { waste }\end{array}$ & Electricity & Heat & Total \\
\hline 2016 & 739 & 217616 & 169066 & 1725 & 1412 & 22 & 509 & 0 & 0 & 391088 \\
2015 & 727 & 163670 & 155732 & 759 & 1212 & 19 & 506 & 0 & 0 & 322624 \\
2014 & 715 & 165014 & 147738 & 1165 & 1192 & 31 & 515 & 0 & 0 & 316369 \\
2013 & 734 & 161649 & 132608 & 1185 & 1254 & 32 & 508 & 0 & 0 & 297970 \\
2012 & 695 & 162368 & 132285 & 481 & 1070 & 18 & 509 & 0 & 0 & 297426 \\
\hline
\end{tabular}

\section{Discussion about energy sustainability indicators for residential area}

Choosing the proper indicators is effective for achieving sustainability in the field of energy. Various types of indicators to improve energy sustainability can be used but which of these indicators are better and more practical in this regard. Hence, an appropriate analysis for selecting indicators to achieve sustainable energy goals is important. We need to know which indicators can be more positive influential to energy sustainability. On the other hand, each analysis should include both quantitative and qualitative indicators that can be better analyzed and selected to achieve energy sustainability. Also, selected indicators should have the sub-indicators that are consistent with the main elements and lead to energy sustainability.

\subsection{Critical interpretation of urban energy develop}

Development of sustainable urbanization plans based on the selection and implementation of urban sustainability indicators should be the priority for each country. These plans if perform and develop inappropriate time and under a proper framework, definitely will have favorable effects for achieving sustainable urbanization. Thus, a set of effective urbanization indicators should be selected and implemented based energy sustainability goals. Fig 4 shows a total schematic of urban energy sustainability and four main divided indexes with relevant indicators it. In this Fig, main indexes as urban energy 
sustainability pillars are in the above of this Fig and relevant indicators to them are in down of this Fig. Also, Fig 3 demonstrates that how energy resource can be divided between the main sectors in the line energy sustainability properly.

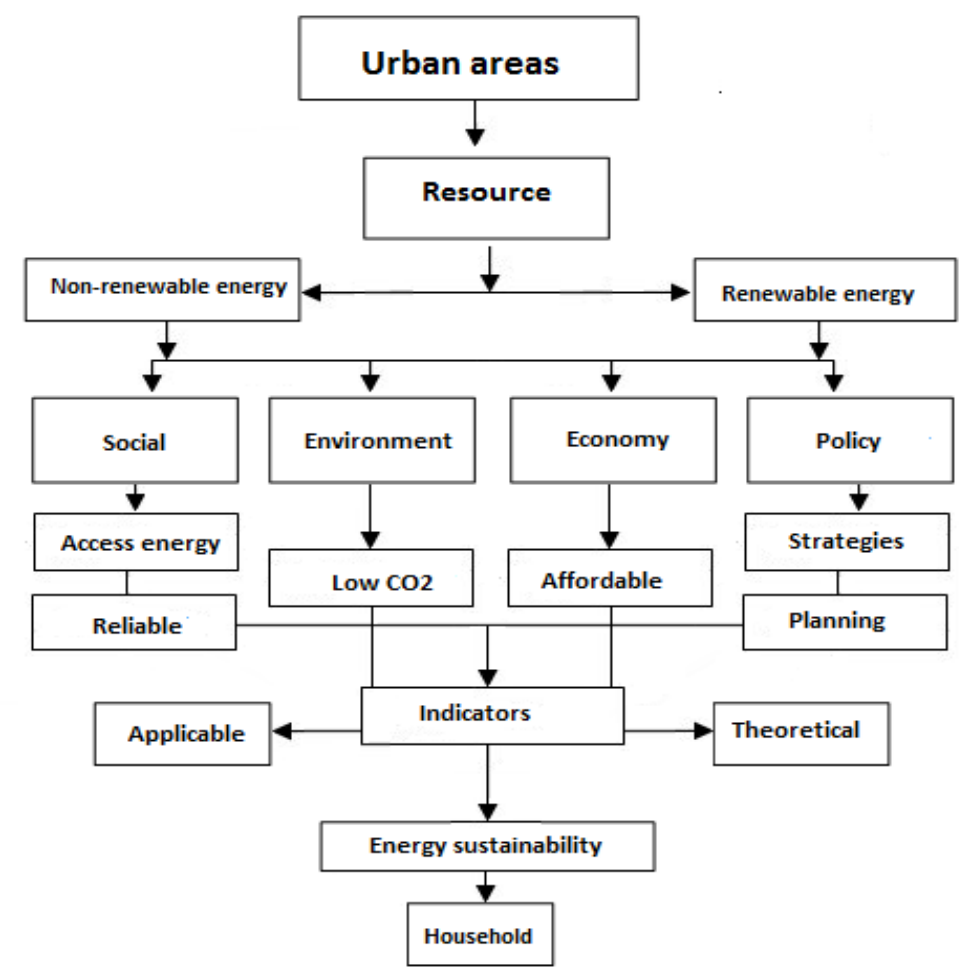

Fig 3. A total schematic of urban energy sustainability and divided indexes with relevant indicators

Table 4 that is designed based Fig 2 shows the four main indexes with related indicators. In this Table, most important indicators as separately for each index have been shown that can be effective to achieve energy sustainability.

Table 4. Four main indexes with related indicators based on Fig 3.

\begin{tabular}{lcccc}
\hline Indicators & Policy & Economy & Environment & Social \\
\hline Strategies and planning & $\sqrt{ }$ & $\sqrt{ }$ & $\sqrt{ }$ & $\sqrt{ }$ \\
Industrial energy intensity & $\sqrt{ }$ & $\sqrt{ }$ & $\mathrm{x}$ & $\mathrm{x}$ \\
Household energy intensity & $\sqrt{ }$ & $\sqrt{ }$ & $\mathrm{x}$ & $\sqrt{ }$ \\
Total energy primary supply & $\sqrt{ }$ & $\mathrm{x}$ & $\mathrm{x}$ & $\mathrm{x}$ \\
Energy intensity & $\sqrt{ }$ & $\mathrm{x}$ & $\mathrm{x}$ & $\mathrm{x}$ \\
Gross domestic product & $\mathrm{x}$ & $\sqrt{ }$ & $\mathrm{x}$ & $\mathrm{x}$ \\
Energy affordable & $\mathrm{x}$ & $\sqrt{ }$ & $\mathrm{x}$ & $\sqrt{ }$ \\
Energy price & $\mathrm{x}$ & $\sqrt{ }$ & $\mathrm{x}$ & $\sqrt{ }$ \\
Total final consumption & $\mathrm{x}$ & $\sqrt{ }$ & $\mathrm{x}$ & $\sqrt{ }$
\end{tabular}


Annual freshwater withdrawals

Forest area

Land area

Reduction of $\mathrm{CO} 2$ and $\mathrm{GHG}$

Share electricity production by fuel fossil

Share electricity production by clean energy

Electrical consumption

Enough investment on clean energy

The efficiency of residential energy use

Access energy

Total final consumption in transport

Share non-renewable in transport

Share renewable in transport

Energy infrastructure and reliability

Renewable energy consumption in household

Resiliency

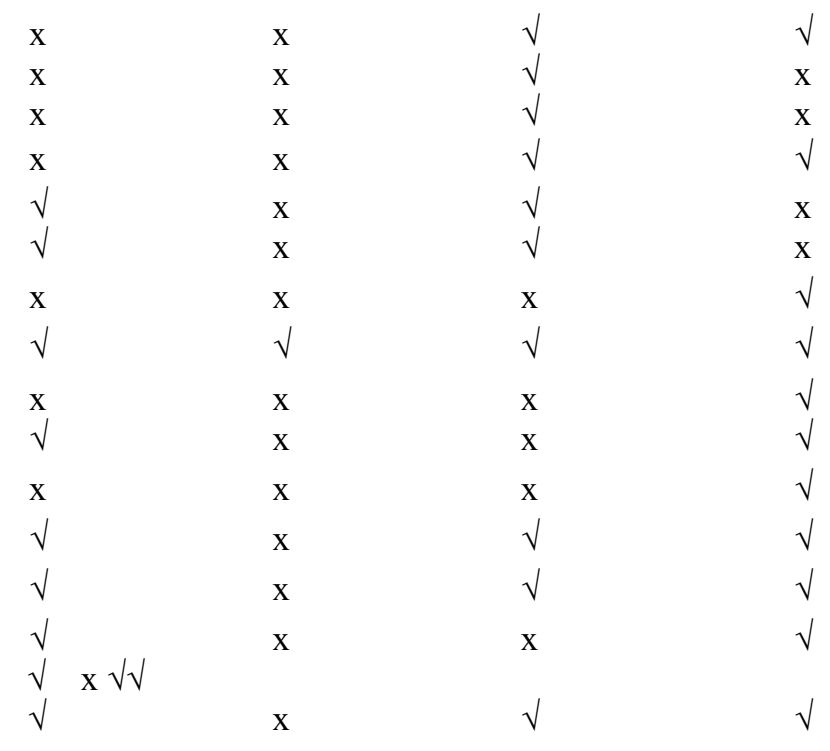

Table 5 shows the city energy sustainability and renewable energy indicators. In this Table, most important indicators related to two index shows separately.

Table 5. City energy sustainability and renewable energy indicators

\begin{tabular}{lcc}
\hline Indicators & City energy sustainability & Renewable energy \\
\hline Electrical consumption & $\sqrt{ }$ & $\sqrt{ }$ \\
Enough investment & $\sqrt{ }$ & $\sqrt{ }$ \\
Energy Burden & $\sqrt{ }$ & $\mathrm{x}$ \\
Access energy & $\sqrt{ }$ & $\mathrm{x}$ \\
Loss of energy & $\sqrt{ }$ \\
New technology & $\sqrt{ }$ & $\sqrt{ }$ \\
Total final consumption in residential & $\sqrt{ }$ & $\sqrt{ }$ \\
Total renewable energy production & $\mathrm{x}$ & $\sqrt{ }$ \\
Reduction of CO2 and GHG & $\sqrt{ }$ & $\sqrt{ }$ \\
Renewable energy potential & $\mathrm{x}$ & $\sqrt{ }$ \\
Energy affordable & $\sqrt{ }$ & \\
\hline
\end{tabular}

\subsection{A new approach to renewable energy}

Renewable energy development shows that there are a positive approach and strategies to exploit their potential (Aslani, Naaranoja, and Zakeri 2012). Also in recent years, using an investment in renewable energy has increased (Khalilnejad and Riahy 2014). Low polluting emissions, potential sources of energy, 
availability are among the important factors that have led to more and more use of renewable energy sources (Kayal and Chanda 2016).

\subsection{Renewable energy potential in Iran}

Iran's has a high potential in renewable energy, especially in solar energy. Because Iran is located on the sun-belt and receives the highest level of solar radiation, thus, it can be used to electricity production (Najafi et al. 2015). Iran has 300 sunny days per year with an average minimum of about 4.5-5.5 $\mathrm{kWh}$ per square meter. It shows the high percentage of solar radiation in this country (Hosseini et al. 2013). Fig 4 shows the maps of Iran's annual average global horizontal irradiance (GHI). As can see Iran has a high potential in solar energy.

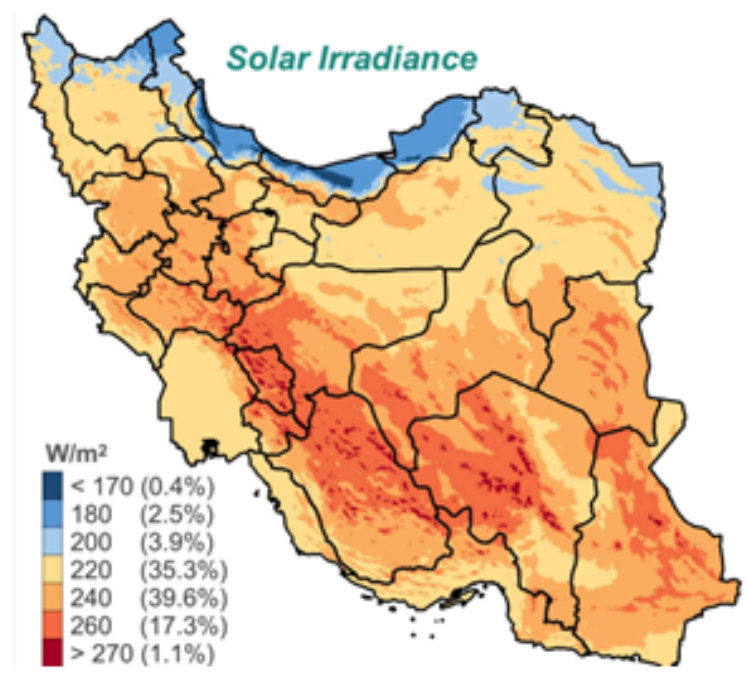

Fig 4. Maps of Iran's annual average global horizontal irradiance [45]

\section{Description studied area}

\subsection{Chabahar city}

Chabahar is one of the strategic city in the Sistan and Baluchistan province and is a well-known port in this zone. It is free trade and industrial zone by Iran's government. It has according to 2018 census 106,739 populations. It is located at Coordinates $2517 \mathrm{~N}$ and $6038^{\prime} \mathrm{E}$ and the 18 meters above sea level. Fig. 5, 
shows the location zone studied on the map of Iran|. As can see the Chabahar is the end of Sistan and Baluchistan province.
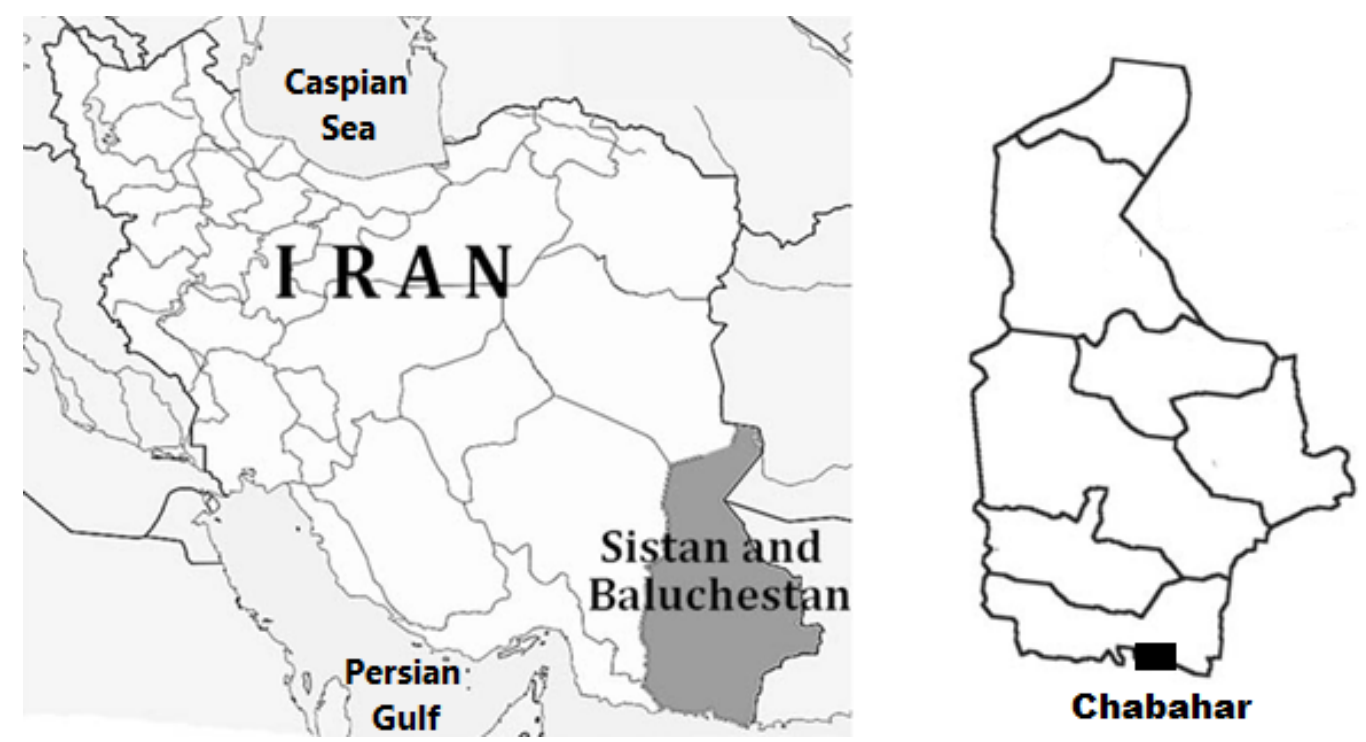

Fig 5. Location zone studied on the map of Iran

\section{Methodology for the objective selection}

Regarding importance improvement energy sustainability through renewable energy especially for residential areas, therefore, in this study, a hybrid energy system including PV, DG, batteries, energy converters using HOMER software is modeled with attention to energy sustainability requirements of Chabahar city like Fig 6 . This study presents a discussion related to energy sustainability and technical analysis of a hybrid system for a city of Iran. We discuss the importance of renewable energy as a reliable way of achieving energy sustainability. This research divided into two main stages. In the first stage, a conceptual discussion regarding energy and policy in the line of UN goals and Urban Themes targets. In the second stage, a technical analysis of a hybrid system for a city of Iran. Fig 6 shows the selected our methodology in this study. 


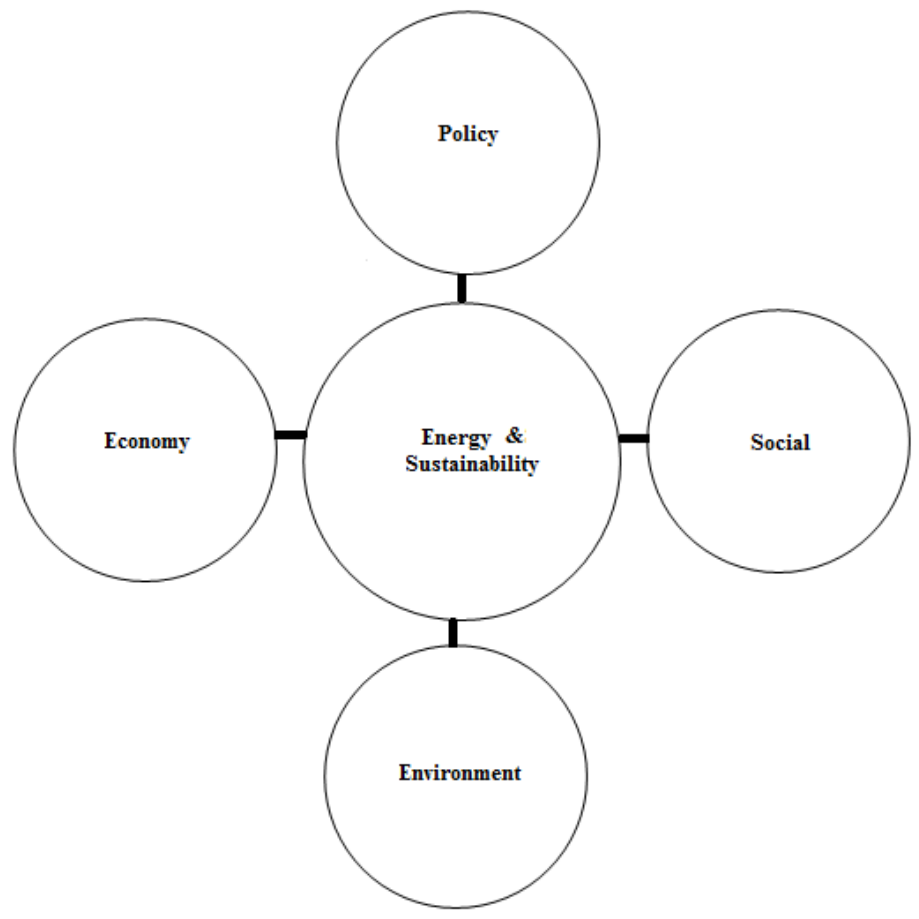

Fig 6. The selected methodology in this study

\subsection{Main cause to select the PV-DG hybrid system for this study}

Because of the construction of renewable power plants directly is depended to natural energies potential as solar radiation, wind speed, and wave power. Therefore PV-DG hybrid system regarding Chabahar potential is most proper than another kind, even though wave energy also can be considered. Fig 7 shows monthly wind speed and solar radiation for Chabahar city. As can see in this Fig 7, regarding low wind speed and high solar radiation, thus, this city only is appropriate to investment on solar energy in order to electrical production. 


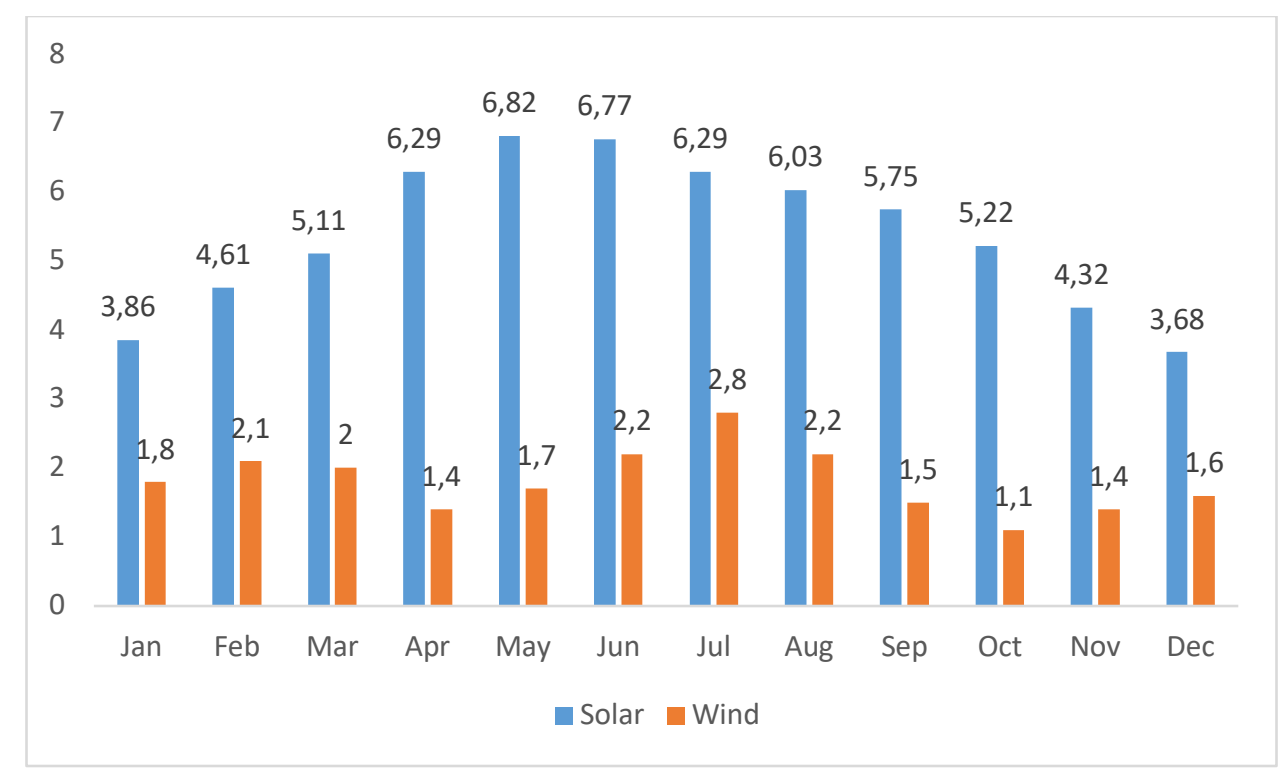

Fig 7. Monthly wind speed and solar radiation for Chabahar city

\subsection{Energy sustainability methodology description (conceptual discuss)}

Without the doubt, four important factors which showed in Fig 6, has a significant impact on energy sustainability and none of them especially policy factor should not be ignored. Regular and appropriate planning by policymakers makes a positive impact on the economy, social and environment factors. Indeed, energy sustainability helps us to better utilizing sustainable energy carriers, improving performance, decreasing negative environmental effects and improving the socioeconomic status. Regarding these explanations, all renewable energy sources like solar, wind, geothermal, hydropower and ocean energy are sustainable because they are abundant and available also proper for our utilization.

\section{Electrical producing by the proposed system}

A schematic of the present system is shown in Fig 8 which has different parts includes PV array, Converter, Battery and Diesel generator. As can see the Load demand of PV-Diesel system is $22.8 \mathrm{kWh} / \mathrm{d}$ and the peak load is estimated at $2.1 \mathrm{~kW}$ for this study. This system is capable of electrical production with 10,575 $\mathrm{kWh} / \mathrm{yr}$ value which $8,447 \mathrm{kWh} / \mathrm{yr}$ of it belongs $\mathrm{PV}$ and 2,128 $\mathrm{kWh} / \mathrm{yr}$ is provided by Diesel system. Fig 8 shows a schematic of the analyzed system that consists of PV, generator, converter, and battery. 


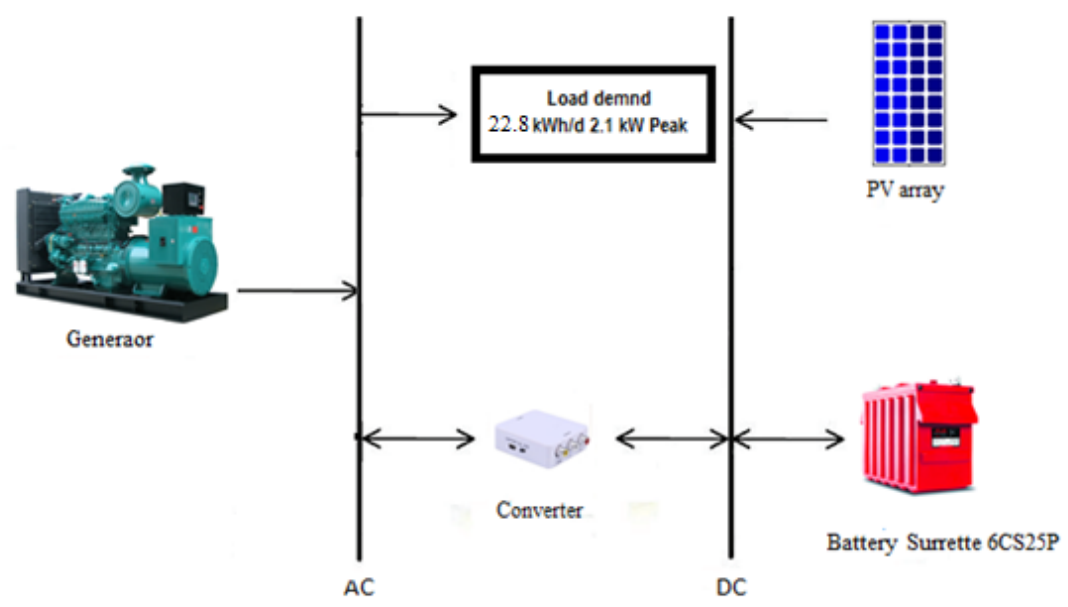

Fig 8. Schematic of the analyzer system 


\section{Result and discussion}

Today most countries are trying to assess their energy systems in order to achieve proper strategies and implementing them based on UN goals and Urban Themes. That in this regard renewable energy can be a suitable way. Indeed, one of the requirements factors to reach energy sustainability status is increasing application of renewable energy. Developing renewable energy lead to reducing $\mathrm{CO} 2$ emission, creating more job opportunity, safety energy, etc. With these explanations, assessment of renewable energy potential, especially in the developing countries, is a necessity for policymakers and energy expert them. In this regard one of the practical software to calculate this work is HOMER. In this study using Homer an economic and technical analysis was performed for implementing a small hybrid system based on renewable energy for an area in Iran. This software presents us with a variety of values consisting of fixed expense and a marginal expense of energy. Actually this software (Homer) based on existing information of geographic seek a proper solution to achieve electrical lthermal loads as well as the operating storage with the lowest expense. HOMER based on data calculates and presents NPC, RF, COE, NPC values. The suggested system is designed in order to serve the entire period project of 5 years over numerous changes, such as components' prices and load demand.

\subsection{Technical analysis of a case study}

One of the best causes to prove that renewable energy can be used for electrical production in the line of energy sustainability is technical analysis by software. Energy software can show how many energies can be extracted from renewable energy systems and could use to energy supply. The technical-economic analysis in this study has been done using homer software. The highest level of solar radiation is equal to $6.820 \mathrm{kWh} / \mathrm{m}^{2} / \mathrm{d}$ per square meter, which has been received in May and the lowest level is 3.680 $\mathrm{kWh} / \mathrm{m}^{2} / \mathrm{d}$ per square meter in December month has been received. Table 6 shows the breakdown of the technical specifications for each component of the system.

Table 6. The technical specifications for each component of system breakdown.

\begin{tabular}{ccccc}
\hline & & & & Electrical \\
$\mathrm{PV}$ & Rated capacity & Mean output & Capacity Factor & production \\
$(\mathrm{kW})$ & $(\mathrm{kW})$ & $(\%)$ & $(\mathrm{kWh} / \mathrm{yr})$
\end{tabular}




\begin{tabular}{lcccc} 
& $\begin{array}{c}\text { Hours of } \\
\text { operation } \\
\text { Generator }\end{array}$ & $\begin{array}{c}\text { Electrical production } \\
(\mathrm{kWh} / \mathrm{yr})\end{array}$ & $\begin{array}{c}\text { Fuel consumption } \\
(\mathrm{L} / \mathrm{yr})\end{array}$ & $\begin{array}{c}\text { Fuel energy input } \\
(\mathrm{kWh} / \mathrm{yr})\end{array}$ \\
& 2,290 & 2,128 & 715 & 7,039 \\
& & & & \\
Battery & Nominal capacity & Losses & Annual throughput & \\
& $(\mathrm{kWh})$ & $(\mathrm{kWh} / \mathrm{yr})$ & $(\mathrm{kWh} / \mathrm{yr})$ & String size \\
& 69,4 & 900 & 4,321 & 1 \\
& & & & \\
Converter & Capacity & Mean output & Hours of operation & Losses \\
& $(\mathrm{kW})$ & $(\mathrm{kW})$ & $(\mathrm{hrs} / \mathrm{yr})$ & Inverter \\
& Inverter & Inverter & Inverter & 734 \\
& 5 & 0.75 & 7,648 & Rectifier \\
& Rectifier & Rectifier & Rectifier & 41 \\
\hline
\end{tabular}

In this research, the load profile was estimated based on related former studies that this assigned the hourly load profile for a residential area. The average electrical energy consumption PV-diesel system is equal to $22.8 \mathrm{kWh} / \mathrm{d}$ as Fig 9 , and the peak load is equal to $2.1 \mathrm{~kW}$. Also, $80 \%$ of the fraction in this system belonged to PV and 20\% to Generator. In this study, PV Array $5 \mathrm{~kW}$, Generator $1 \mathrm{~kW}, 10$ Battery the kind of Surrette 6CS25P, Inverter and Rectifier $5 \mathrm{~kW}$ used for this system. For more explanation of Fig. 9, it can be mentioned that the lowest electricity production with $1.18 \mathrm{~kW}$ was observed in January, February and May months and the highest electricity production was observed in March and September months with $1.25 \mathrm{~kW}$.

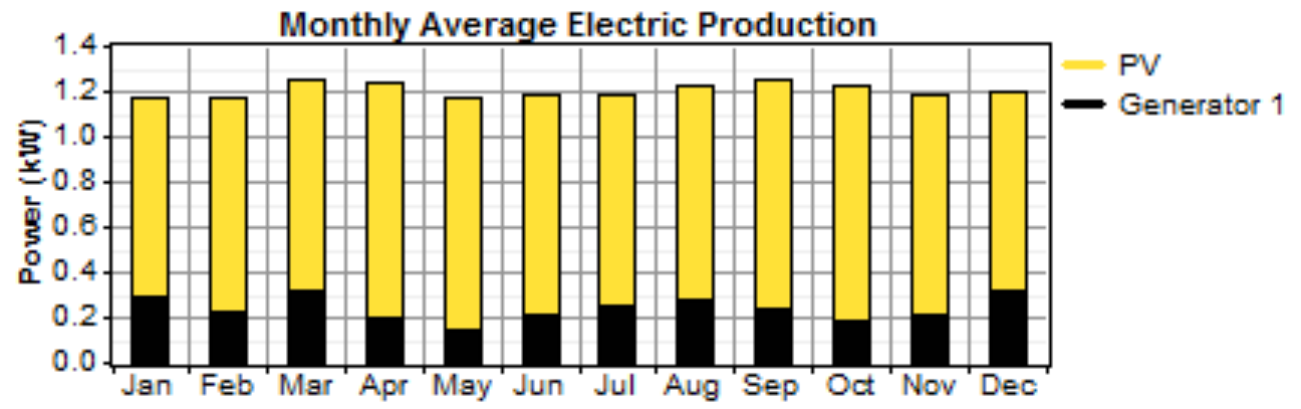

Fig 9. Monthly Average Electric Production of PV-generator hybrid for Chabahar

\subsection{Comparison between this work with some other near studies from the electrical production} point of view 
Since Iran country is a high potential country for constructing wind power station, solar power station, etc. In this regard, many works close to our works carried out. Table 7 shows a comparison between this study with six near work with regard a ratio of electrical production than initial cost. As it is clear in this Table, the amount of electricity production by PV-DG system is remarkable for these areas.

Table 7. A comparison between this work and other close work based on electrical production

\begin{tabular}{|c|c|c|c|c|c|}
\hline City & System & Total electrical production $(\mathrm{kWh} / \mathrm{yr})$ & Initial cost (\$) & Carbon dioxide (kg/yr) & Reference \\
\hline Chabahar & PV-DG & 10575 & 21000 & 1,884 & $\begin{array}{c}- \\
\text { (Razmjoo and } \\
\text { Davarpanah }\end{array}$ \\
\hline Damghan & PV-DG & 9876 & 31000 & 2402 & $\begin{array}{c}\text { 2018) } \\
\text { (Mostafaeipour, } \\
\text { Qolipour, and } \\
\text { Mohammadi }\end{array}$ \\
\hline Dezful & PV-WDG & 35085 & 27720 & 26936 & $\begin{array}{c}\text { 2016) } \\
\text { (Mostafaeipour, } \\
\text { Qolipour, and } \\
\text { Mohammadi }\end{array}$ \\
\hline shushtar & PV-WDG & 35050 & 27720 & 27008 & $\begin{array}{c}\text { 2016) } \\
\text { (Mostafaeipour, } \\
\text { Qolipour, and } \\
\text { Mohammadi }\end{array}$ \\
\hline Hendijan & PV-WDG & 34903 & 27720 & 27136 & $\begin{array}{l}\text { 2016) } \\
\text { (Razmjoo } \\
\text { and } \\
\text { Davarpanah }\end{array}$ \\
\hline Damghan & PV-WDG & 12794 & 20300 & 2633 & 2018) \\
\hline
\end{tabular}

\subsection{Comprehensive discussion by attention energy political sustainability}

Since natural energy resources such as oil and gas are limited and have a high percentage of air pollution which hurt to environment extremely, therefore, have needed a suitable substitute. On the other hand, regarding a lack of policy stable in the countries producing oil \& gas and lack enough resource to energy supply in most countries, therefore it is a necessity to have an accounted plan to achieve energy sustainability for present and future generation based on UN goals and Urban Themes targets. All 17 goals on UN and 14 targets of Urban Themes are emphases on sustainable development based most important parameters that humanity needs for a proper life in the future. In this regard, all governments around the 
world have adopted ambitious goals to improve the share of renewable energy for providing a part of the required energy and reduce greenhouse gases to achieving energy sustainability. Also governments by regular planning and using energy experts and policymaker's views, assigned effective indicators to achieve energy sustainability. Achieving energy sustainability is extremely dependent on implementing appropriate indicators in the line of the social, environmental and economic dimensions. Parameters such as energy affordable, clean energy, energy access, enough energy, etc., are the most important issues of inhabitants in residential areas. Assigning proper indicators to develop urban area is a key role factor and a priority for all inhabitants. Energy indicators as a strong tool in hand of policymakers can help us to have the better life in the future if these indicators implement properly. Policymakers and energy experts should investigate suitable planning as a serious duty for support of urban areas. Also, the utilization of renewable energy should be extended with an effective policy and as a reliable way to supply a part of the required energy for the countries that have not sufficient resource for a good future. These indexes with indicators make a chain of energy sustainability for residential areas. This Fig as well as show relation between all indexes and indicators in the line of on UN goals and Urban Themes targets. All benefits using renewable energy based on parameters social, Economic and environmental of sustainable development are shown in this Fig. Indeed, the main objective of this Fig is energy access in the best possible state for residential inhabitants as secure, reliable, abundant, accessible and affordable. 


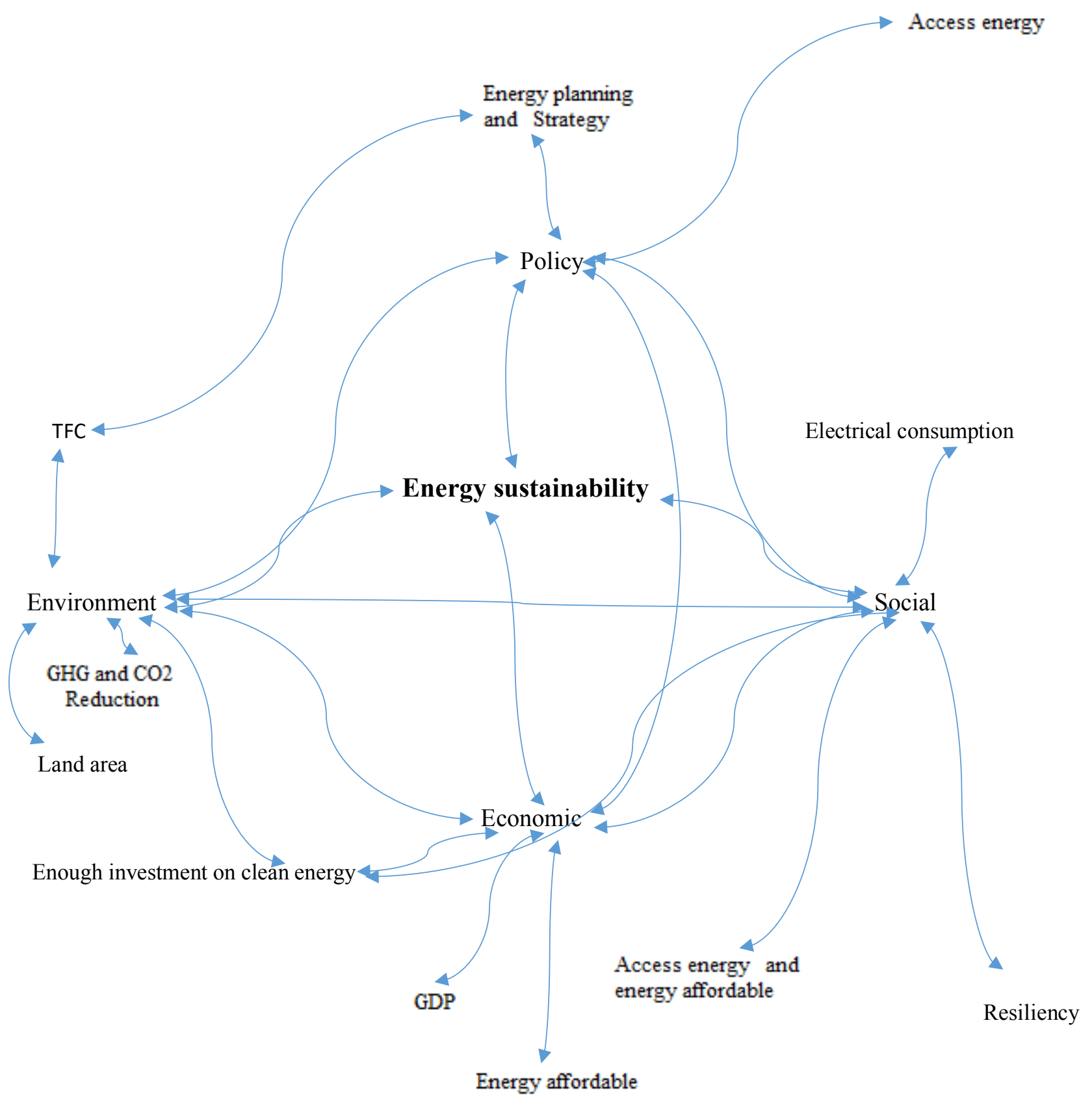

Fig 10. Energy sustainability dynamic schematic 


\section{Conclusion}

One of the proper ways to achieve energy sustainability is the use of renewable energy which has a very high potential and is a suitable substitute for fossil fuel resources. Since developing countries more needs to regular planning with effective policy to reach this goal, hence, all existing aspects in this regard should be investigated by policymakers and energy experts. Although achievement to energy sustainability and sustainable development is not easy, some positive actions such as appropriate policy and using clean energy for residential areas can be influential in the path of received to this target in future. In this study has been presented a comprehensive discussion related to energy sustainability and a technical-economic analysis on combined utilization PV and DG for Chabahar city. Firstly, energy sustainability explained precisely with proper indicators especially for the residential area and with emphases on renewable energy, then a case study investigated from the energy point of view. Chabahar city has high potential in solar energy; this can be investigated to constructing a solar power station in order to electrical production. The diagram of horizontal radiation for this city showed that the highest level of solar radiation is 6.820 $\mathrm{kWh} / \mathrm{m}^{2} / \mathrm{d}$ and the lowest level is $3.680 \mathrm{kWh} / \mathrm{m}^{2} / \mathrm{d}$ per square meter which has been recorded in May and December months respectively. The average of solar radiation per year was obtained for this city 5.4 $\mathrm{kWh} / \mathrm{m} 2 / \mathrm{d}$. This analysis shows that this site has a desirable solar potential. Also, technical analysis of this system shows this city has a high capacity for electrical generation by PV-diesel system. Total electrical production was estimated $10,575 \mathrm{kWh} / \mathrm{yr}$ that $8,447 \mathrm{kWh} / \mathrm{yr}$ belongs to $\mathrm{PV}$ and 2,128 $\mathrm{kWh} / \mathrm{yr}$ belongs to diesel generator system(DG). Therefore, energy experts and policymakers can with regard this potential of energy in Chabahar, make appropriate acts such as attracting energy investors achieve energy sustainability for this city.

\section{Reference:}

Alazraque-Cherni, Judith. 2008. "Renewable energy for rural sustainability in developing countries." Bulletin of Science, Technology \& Society 28 (2):105-114. 
Aslani, Alireza, Marja Naaranoja, and Behnam Zakeri. 2012. "The prime criteria for private sector participation in renewable energy investment in the Middle East (case study: Iran)." Renewable and Sustainable Energy Reviews 16 (4):1977-1987.

Bäckstrand, Karin. 2003. "Civic science for sustainability: reframing the role of experts, policy-makers and citizens in environmental governance." Global Environmental Politics 3 (4):24-41.

Bishoge, Obadia, Lingling Zhang, and Witness Mushi. 2018. "The potential renewable energy for sustainable development in Tanzania: A review." Clean Technologies 1 (1):70-88.

Bogdanov, Dmitrii, and Christian Breyer. 2016. "North-East Asian Super Grid for $100 \%$ Renewable Energy supply: Optimal mix of energy technologies for electricity, gas and heat supply options." Energy Conversion and Management 112:176-190.

Boran, FE, K Boran, and T Menlik. 2012. "The evaluation of renewable energy technologies for electricity generation in Turkey using intuitionistic fuzzy TOPSIS." Energy Sources, Part B: Economics, Planning, and Policy 7 (1):81-90.

Boudewijns, Tom, Marco Piccinini, Paul Degraeve, Armin Liebens, and Dirk De Vos. 2015. "Pathway to vinyl chloride production via dehydrochlorination of 1, 2-dichloroethane in ionic liquid media." ACS Catalysis 5 (7):4043-4047.

Çakir, Uğur, Kemal Comakli, and Fikret Yüksel. 2012. "The role of cogeneration systems in sustainability of energy." Energy Conversion and Management 63:196-202.

Chmiel, Zbigniew, and Subhes C Bhattacharyya. 2015. "Analysis of off-grid electricity system at Isle of Eigg (Scotland): Lessons for developing countries." Renewable Energy 81:578-588.

Clemens, Harry, Rob Bailis, Anne Nyambane, and Victoria Ndung'u. 2018. "Africa Biogas Partnership Program: A review of clean cooking implementation through market development in East Africa." Energy for Sustainable Development.

Davarpanah, Afshin. 2018. "Feasible analysis of reusing flowback produced water in the operational performances of oil reservoirs." Environmental Science and Pollution Research 25 (35):3538735395. doi: 10.1007/s11356-018-3506-9.

Dincer, Furkan. 2011. "The analysis on photovoltaic electricity generation status, potential and policies of the leading countries in solar energy." Renewable and Sustainable Energy Reviews 15 (1):713720.

Doelle, Meinhard, and A John Sinclair. 2006. "Time for a new approach to public participation in EA: Promoting cooperation and consensus for sustainability." Environmental Impact Assessment Review 26 (2):185-205.

Ellabban, Omar, Haitham Abu-Rub, and Frede Blaabjerg. 2014. "Renewable energy resources: Current status, future prospects and their enabling technology." Renewable and Sustainable Energy Reviews 39:748-764.

Godina, Radu, Eduardo MG Rodrigues, Edris Pouresmaeil, João CO Matias, and João PS Catalão. 2018. "Model predictive control home energy management and optimization strategy with demand response." Applied Sciences 8 (3):408.

Gugul, Gul Nihal, Merih Aydinalp Koksal, and V Ismet Ugursal. 2018. "Techno-economical analysis of building envelope and renewable energy technology retrofits to single family homes." Energy for Sustainable Development 45:159-170.

Guichi, Amar, Abdelaziz Talha, El Madjid Berkouk, and Saad Mekhilef. 2018. "Energy Management and Performance Evaluation of Grid Connected PV-Battery Hybrid System with Inherent Control Scheme." Sustainable Cities and Society.

Halabi, Laith M, and Saad Mekhilef. 2018. "Flexible hybrid renewable energy system design for a typical remote village located in tropical climate." Journal of Cleaner Production 177:908-924. 
Halabi, Laith M, Saad Mekhilef, Lanre Olatomiwa, and James Hazelton. 2017. "Performance analysis of hybrid PV/diesel/battery system using HOMER: A case study Sabah, Malaysia." Energy conversion and management 144:322-339.

Han, Xiaojuan, Zekun Zhao, Jianlin Li, and Tianming Ji. 2017. "Economic evaluation for wind power generation-hybrid energy storage system based on game theory." International Journal of Energy Research 41 (1):49-62.

Helm, Dieter. 2002. "Energy policy: security of supply, sustainability and competition." Energy policy 30 (3):173-184.

Hossain, Monowar, Saad Mekhilef, and Lanre Olatomiwa. 2017. "Performance evaluation of a standalone PV-wind-diesel-battery hybrid system feasible for a large resort center in South China Sea, Malaysia." Sustainable cities and society 28:358-366.

Hosseini, Seyed Ehsan, Amin Mahmoudzadeh Andwari, Mazlan Abdul Wahid, and Ghobad Bagheri. 2013. "A review on green energy potentials in Iran." Renewable and Sustainable Energy Reviews 27:533-545.

Jahangiri, Mehdi, Omid Nematollahi, Ahmad Sedaghat, and Mohsen Saghafian. 2015. "Technoeconomical assessment of renewable energies integrated with fuel cell for off grid electrification: A case study for developing countries." Journal of Renewable and Sustainable Energy 7 (2):023123.

Jahangiri, Mehdi, Rana Abdelahi Rizi, and Akbar Alidadi Shamsabadi. 2018. "Feasibility study on simultaneous generation of electricity and heat using renewable energies in Zarrin Shahr, Iran." Sustainable Cities and Society 38:647-661.

Kabir, Ehsanul, Pawan Kumar, Sandeep Kumar, Adedeji A Adelodun, and Ki-Hyun Kim. 2018. "Solar energy: Potential and future prospects." Renewable and Sustainable Energy Reviews 82:894900.

Kayal, Partha, and CK Chanda. 2016. "Strategic approach for reinforcement of intermittent renewable energy sources and capacitor bank for sustainable electric power distribution system." International Journal of Electrical Power \& Energy Systems 83:335-351.

Kaygusuz, Kamil. 2012. "Energy for sustainable development: A case of developing countries." Renewable and Sustainable Energy Reviews 16 (2):1116-1126.

Khalilnejad, A, and GH Riahy. 2014. "A hybrid wind-PV system performance investigation for the purpose of maximum hydrogen production and storage using advanced alkaline electrolyzer." Energy Conversion and Management 80:398-406.

Maheshwari, Zeel, and Rama Ramakumar. 2017. "Smart integrated renewable energy systems (SIRES): A novel approach for sustainable development." Energies 10 (8):1145.

Mainali, Brijesh, Shonali Pachauri, Narasimha D Rao, and Semida Silveira. 2014. "Assessing rural energy sustainability in developing countries." Energy for Sustainable Development 19:15-28.

Marquez-Ballesteros, Maria-Jose, Llanos Mora-López, Pau Lloret-Gallego, Andreas Sumper, and Mariano Sidrach-de-Cardona. 2018. "Measuring Urban Energy Sustainability and its Application to Two Spanish Cities: Malaga and Barcelona." Sustainable Cities and Society.

Mostafaeipour, Ali, Mojtaba Qolipour, and Kasra Mohammadi. 2016. "Evaluation of installing photovoltaic plants using a hybrid approach for Khuzestan province, Iran." Renewable and Sustainable Energy Reviews 60:60-74.

Najafi, Gholamhasan, Barat Ghobadian, Rizalman Mamat, Talal Yusaf, and WH Azmi. 2015. "Solar energy in Iran: Current state and outlook." Renewable and Sustainable Energy Reviews 49:931-942.

Neves, Ana Rita, and Vítor Leal. 2010. "Energy sustainability indicators for local energy planning: Review of current practices and derivation of a new framework." Renewable and Sustainable Energy Reviews 14 (9):2723-2735. 
Novan, Kevin. 2015. "Valuing the wind: renewable energy policies and air pollution avoided." American Economic Journal: Economic Policy 7 (3):291-326.

Razmjoo, Ali, and Afshin Davarpanah. 2018. "Developing various hybrid energy systems for residential application as an appropriate and reliable way to achieve Energy sustainability." Energy Sources, Part A: Recovery, Utilization, and Environmental Effects:1-14.

Razmjoo, Ali, Mojtaba Qolipour, Reza Shirmohammadi, S Mohammadreza Heibati, and Iraj Faraji. 2017. "Techno-economic evaluation of standalone hybrid solar-wind systems for small residential districts in the central desert of Iran." Environmental Progress \& Sustainable Energy 36 (4):1194-1207.

Sen, Souvik, and Sourav Ganguly. 2017. "Opportunities, barriers and issues with renewable energy development-A discussion." Renewable and Sustainable Energy Reviews 69:1170-1181.

Shezan, SK A, S Julai, MA Kibria, KR Ullah, R Saidur, WT Chong, and RK Akikur. 2016. "Performance analysis of an off-grid wind-PV (photovoltaic)-diesel-battery hybrid energy system feasible for remote areas." Journal of Cleaner Production 125:121-132.

Sovacool, Benjamin K, and Ishani Mukherjee. 2011. "Conceptualizing and measuring energy security: A synthesized approach." Energy 36 (8):5343-5355.

Srivastava, Rachit, and Vinod Kumar Giri. 2016. "Optimization of Hybrid Renewable Resources using HOMER." International Journal of Renewable Energy Research (IJRER) 6 (1):157-163.

Šúri, Marcel, Thomas A Huld, Ewan D Dunlop, and Heinz A Ossenbrink. 2007. "Potential of solar electricity generation in the European Union member states and candidate countries." Solar energy 81 (10):1295-1305.

Vahdatpour, Shoeleh, Shokoofeh Behzadfar, Leila Siampour, Elahe Veisi, and Mehdi Jahangiri. 2018. "Evaluation of Off-grid Hybrid Renewable Systems in the Four Climate Regions of Iran." Journal of Renewable Energy and Environment 4 (1):61.

Wesselink, Anna, Jouni Paavola, Oliver Fritsch, and Ortwin Renn. 2011. "Rationales for public participation in environmental policy and governance: practitioners' perspectives." Environment and Planning A 43 (11):2688-2704.

Zhou, Wei, Chengzhi Lou, Zhongshi Li, Lin Lu, and Hongxing Yang. 2010. "Current status of research on optimum sizing of stand-alone hybrid solar-wind power generation systems." Applied Energy 87 (2):380-389. 